\title{
BETON ICÇINDE ÇELIKK TEL KULLANARAK BETONARME BİNALARIN DEPREM PERFORMANSININ ARTIRILMASI
}

\author{
${ }^{1}$ Musa Hakan ARSLAN, ${ }^{2}$ Gamze DOĞAN, ${ }^{3}$ Kismet DABANLI, \\ ${ }^{4}$ Mustafa ÖZDEMIR, ${ }^{5}$ Hasan DIVARCI \\ ${ }^{1}$ Doç. Dr., Selçuk Üniversitesi, Mühendislik Fakültesi, İnşaat Mühendisliği Böl.,Kampüs, KONYA \\ ${ }^{2}$ Arş.Gör., Selçuk Üniversitesi, Mühendislik Fakültesi, İnşaat Mühendisliği Böl. Kampüs, KONYA \\ 3-5inşaat Mühendisi \\ 1mharslan@selcuk.edu.tr, ${ }^{2}$ gamze@selcuk.edu.tr, ${ }^{3}$ kismet.dabanli@hotmail.com, \\ ${ }^{4}$ mustafa_ozdemir_912@hotmail.com, ${ }^{5}$ ins.müh.hasandivarci@hotmail.com
}

(Geliş/Received: 05.08.2014; Kabul/Accepted in Revised Form: 30.10.2014)

ÖZET: Bu çalışmada betonarme çerçevelerin deprem yükleri altında performansının artırılması için beton içinde belirli oranlarda çelik tel kullanılması amaçlanmıştır. Bu amaç doğrultusunda TDY-2007 normlarına uygun 1/3 geometrik ölçekli üç adet iki katlı tek açıklıklı betonarme çerçeve üretilmiştir. Çerçevelerden biri referans olarak düşünülmüş $\left(\mathrm{S}_{1}\right)$ ve içinde çelik tel olmayan normal beton kullanılarak imal edilmiştir. Diğer iki çerçevenin birinde $\left(\mathrm{S}_{2}\right) \mathrm{m}^{3^{\prime}}$ de $30 \mathrm{~kg}$, diğerinde ise $\left(\mathrm{S}_{3}\right) \mathrm{m}^{3^{\prime}}$ de $60 \mathrm{~kg}$ çelik tel kullanılmıştır. Üretilen betonarme çerçeveler, depreme benzeştirilmiş tersinir tekrarlanır yatay yükler altında test edilmiş, betonarme çerçevelerin yatay yük taşıma kapasiteleri ve rijitlikleri tespit edilmiştir. Çalışma sonunda $S_{2}$ numunesinin yatay yük taşıma kapasitesinin ve başlangıç rijitliği açısından deprem performansının $S_{1}$ ve $S_{3}{ }^{\prime}$ e göre daha iyi olduğu görülmüştür.

Anahtar Kelimeler: Performans, Deprem, Betonarme, Çelik Tel, Deneysel Çalışma

\section{Improving Seismic Performance of Reinforced Concrete Buildings with Using Steel Fibers}

\begin{abstract}
In this study, in order to improve the seismic performance of reinforced concrete frames using the specific amount of steel fiber in concrete is aimed. In this scope, three $1 / 3$ geometric scaled reinforced concrete have produced according to the TEC-2007 rules. One of the three frames is called as a reference $\left(\mathrm{S}_{1}\right)$ which has been produced with normal concrete. The others have produced with different fiber amount in the concrete. The selected amount is $30 \mathrm{~kg} / \mathrm{m}^{3}$ and $60 \mathrm{~kg} / \mathrm{m}^{3}$ for $S_{2}$ and $S_{3}$, respectively. The three different specimens have been tested under earthquake resembling cycling lateral loading, the stiffness and lateral loading capacities have been obtained, experimentally. At the end of the study, it has been seen that the seismic performance of $S_{2}$ is better than $S_{1}$ and $S_{3}$ with respect to initial stiffness and lateral loading capacity.
\end{abstract}

Keywords: Performance, Earthquake, Reinforced Concrete, Steel Fiber, Experimental Study

\section{GİRIŞ̧ (INTRODUCTION)}

Deprem riski yüksek olan bölgelerde yapılacak olan betonarme binaların en büyük sorunu deprem sırasında ortaya çıkacak olan enerjinin yapısal elemanlar tarafından istenilen seviyede tüketilememesidir. Deprem enerjisinin yapı içinde tüketilmesi taşıyııı sistem elemanları olan kolon, kiriş ve perdelerde plastik mafsal oluşumu ile ilgilidir. Plastik mafsal ile yapıda deprem sırasında oluşan 
enerjinin sönümlenmesi mümkün olabilmektedir. Deprem yönetmeliklerinde plastik mafsal oluşma kapasitesi olan bölgelerde farklı tasarım kriterlerine göre donatıların yerleştirilmesi ve böylece mafsallaşmanın bu bölgelerde daha rahat oluşması istenmektedir. Betonun gerek deformasyon gerekse diğer mekanik özelliklerinin iyileştirilmesi, kesitin daha sünek davranarak enerji yutma kapasitesinin artması anlamına gelmektedir.

Çelik tel kullanımı ile betonun düşük olan çekme mukavemeti değeri artmakta, geleneksel donatı uygulaması sırasında oluşabilecek hataların bir kısmı kapatılabilmekte, servis yükleri altında oluşması beklenen kılcal çatlaklar ise oluşmamaktadır. Literatürde çelik tel kullanımı ile betonun mekanik özelliklerinin değişimi üzerine çok sayıda çalışma olsa da [Taşdemir, 1999, Aktaş, 2007, Ünal ve diğ., 2007] betonarme çerçevelerde global deprem davranışı üzerine bir çalışma yapılmamış olması bu çalışmanın temel motivasyon kaynağıdır.

$\mathrm{Bu}$ çalışmada kullanılacak olan çelik teller betonun mekanik özeliklerini belirgin biçimde arttırmasına rağmen maliyetini de arttırmaktadır. Fakat yapı elemanlarının özellikle deprem sonrasında görmüş oldukları hasarlar ve yapıların deprem sonrasında onarım/güçlendirme maliyetleri düşünülecek olursa beton içinde belirli bir oranda kullanılacak olan çelik telin uzun süreli ekonomi getirebileceği düşünülmektedir.

Çalışmada ayrıca beton içinde kullanılacak olan çelik tellerin geri dönüşüm özelliğine sahip olmasının tel malzeme maliyetini azaltması, atık malzeme kullanımının yaygınlaştırılması ve beton gibi yapılarda kullanılan ana taşıyıcı sistem malzemesi içinde geri dönüşümlü malzeme kullanımının yaygınlaştırılması açısından da son derece önemli olduğu da vurgulanmaktadır.

Özellikle deprem bölgelerinde inşa edilecek olan gerek konvansiyonel gerekse prefabrike betonarme yapıların deprem etkisi altında rahat bir şekilde enerji yutmaları bunun içinde deplasman kapasitelerinin yüksek olması istenmektedir. Bu çalışma neticesinde, beton içine karıştırılacak olan belirli oranda çelik tellerin taşıyıcı sistemin çatlak oluşumunu geciktirip, yapının sünekliği ve yük taşıma kapasitesini bir miktar artırabilirse yapı sahibinin isteği üzerine yeni projelendirilecek olan binalarda çelik tel katkılı beton kullanılabilecektir.

Literatürde şimdiye kadar beton içinde belirli bir oranda çelik tel kullanımı ile betonarme binaların deprem performansının nasıl değişebileceğine yönelik bir araştırma yapılmamış araştırmalar daha çok çelik tel katılı betonların mekanik davranışları üzerine yoğunlaşmıştır. Çelik tek katkılı beton davranışının irdelendiği araştırmalarda [Ramesh ve diğ., 2003, Craig ve Patel, 1982] özellikle çelik tel kullanımıyla betonun davranışında ve çatlak gelişiminde değişiklikler gözlemlenmiştir. Çalışmalarda çelik telin betonun çatlak gelişimini durdurduğu yada sınırlandırdığı sonucuna ulaşılmıştır. Ayrıca çelik telin betonun sünekliğinde ve basınç dayanımında olumlu etki yaptığı görülmüştür.

Özellikle eksenel yüklü elemanlarda fiberin betonda oluşacak çatlakların sınırlandırılması yönünde yaptığı etki basınç altındaki bir eleman için bir sargi etkisi yaratmaktadır. Oluşan bu etki ile elemanın sünekliği ve dolayısıyla sistemin sünekliği artmaktadır [Shah ve Rangan,1970].

$\mathrm{Bu}$ çalışmada betonun mekanik özelliklerinin iyileştirilerek, betonarme çerçevenin deprem yükleri altında yapacağı deplasmanın ve enerji tüketme miktarının artırılması hedeflenmektedir. Çalışmanın temel amacı çelik tel kullanımının betonarme binalarda oluşturduğu performans değişikliğini gözlemlemek, özellikle yüksek ve düşük oranlardaki çelik tellerin hangisinin daha avantajlı olduğunu irdeleyebilmek ve betonarme yapıların deprem davranışında bu malzemenin ne oranda etki sahibi olabileceğini anlamaktır.

\section{DENEYSEL YÖNTEM VE VERI SETINIIN HAZIRLANMASI (EXPERIMENTAL METHODS AND PREPARATION OF DATA SET)}

Deneylerde kullanılmak üzere iki katlı tek açıklıklı 1/3 geometrik ölçekli üç adet betonarme çerçeve üretilmiştir. Çerçevelerde kat yüksekliği $900 \mathrm{~mm}$, çerçeve açıklı̆̆ ise dıştan dişa 1500 mm'dir. Kiriş ve kolonların boyutları 150x150 mm'dir. Betonarme çerçeve 500x700x2500 mm boyutlarında bir temel kirişine mesnetlenmiştir. Tüm deney elemanlarında çerçevelerin geometrik boyutları ve donatı 
detayları aynıdır. Betonarme çerçevelerde ki donatı detayları ve düzeni yürürlükte olan standartlara göre ayarlanmıştır [TDY, 2007, TS-500, 2000].Dolayısıyla çerçevelerde aşağıdaki özellikler aranacaktır;

- $\quad$ Kolonları kirişlerden daha güçlü,

- $\quad$ Elemanlarda ilk önce eğilme hasarı daha sonra ise kesme hasarı oluşacak,

- Bindirme boyları ve kenetlenme açısından birleşim bölgelerinde problem olmayan,

- $\quad$ Etriye sıklaştırma kurallarına uyulmuş,

- $\quad$ Betonve donatı minimum mekanik özellikleri şartname alt limitini sağlayan.

Şekil 1'de üretilmiş olan çerçevelerin detayları verilmiştir. Numunelerde yatay ve düşey donatılarını tümü nervürlüdür ve donatıların minimum deneysel akma dayanımı $420 \mathrm{MPa}$ 'dır. Kolonlarda kesit içine simetrik olarak dağılmış $8 \odot 8$ kirişlerde ise altta ve üstte toplam $6 \odot 8$ boyuna S420 donatısı mevcuttur. Kolon ve kiriş boyutları ile boyuna donatısı seçilirken kuvvetli kolon zayıf kiriş ilkesinin sağlanması amaçlanmıştır. Kolonlarda boyuna donatı oranı \%1.77, kirişlerde mesnet ve açıklıkta çekme donatısı oranı ise $\% 0.75$ 'dir ve TDY-2007 ile TS-500 sınırları içinde kalmaktadır. Kolon ve kirişlerde enine donatı olarak $₫ 4 / 4 / 7$ donatı seçilmiştir. Sıklaştırma bölgesi ve etriye aralıkları yine yönetmelik şartlarına uygundur. Etriyelerin kancası 135 derece bükümlü olacak şekilde hazırlanacaktır. Referans numunede kullanılacak olan beton C25 olarak hedeflenmiştir. Betonda maksimum agrega çapı $16 \mathrm{~mm}$ olarak belirlenmiştir.Her bir deney elemanı için alınan üç adet küp ve bir adet silindir numunenin 28. günde basınç mukavemetleri bulunmuştur. Çizelge 1'de numunelerden elde edilen sonuçlar verilmiştir.

Çizelge 1.Beton Basınç Dayanımları

(Compressive Strength of Concrete )

\begin{tabular}{ccccc}
\hline & $\begin{array}{c}\mathbf{N}-\mathbf{1} \\
\mathbf{( 1 5 / 1 5} \\
\mathbf{c m})\end{array}$ & $\begin{array}{c}\mathbf{N - 2} \\
\mathbf{( 1 5 / 1 5} \\
\mathbf{c m})\end{array}$ & $\begin{array}{c}\mathbf{N}-\mathbf{3} / \mathbf{1 5} \\
\mathbf{c m})\end{array}$ & $\begin{array}{c}\mathbf{N}-\mathbf{4} \\
\mathbf{1 5 / 3 0} \\
\mathbf{c m})\end{array}$ \\
\hline $\mathrm{S}_{\mathbf{1}}$ & $22 \mathrm{MPa}$ & $23 \mathrm{MPa}$ & $24 \mathrm{MPa}$ & $18 \mathrm{MPa}$ \\
\hline $\mathrm{S}_{\mathbf{2}}$ & $25 \mathrm{MPa}$ & $25 \mathrm{MPa}$ & $22 \mathrm{MPa}$ & $19 \mathrm{MPa}$ \\
\hline $\mathrm{S}_{3}$ & $22 \mathrm{MPa}$ & $22 \mathrm{MPa}$ & $24 \mathrm{MPa}$ & $20 \mathrm{MPa}$ \\
\hline
\end{tabular}

Kiriş ve kolonlarda kesme kapasiteleri oldukça yüksektir. Kolon kiriş birleşim bölgeleri ile kolon temel birleşiminde donatının sıyrılmaması için kenetlenme boyları minimum şartları yerine getirecek şekilde hesaplanmıştır. Çizelge 2'de ise deneyde kullanılmak için üretilen numunelerin genel özellikleri verilmiştir.

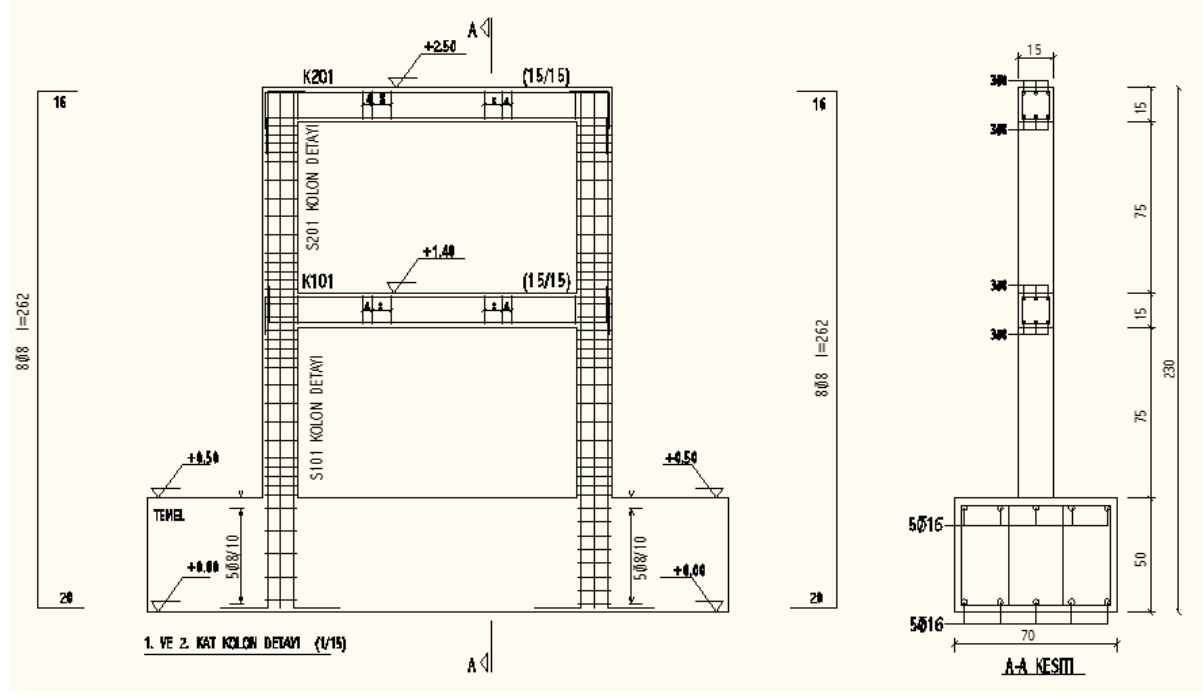

Şekil 1. Üretilmiş Olan Betonarme Çerçeve 


\section{(Produced concrete frame)}

Numuneler Selçuk Ün. Müh. Fakültesi İnşaat Mühendisliği Bölümü Depren Araştırma Laboratuarında üretilmiştir. Üretilen üç adet çerçevenin üretim aşaması Şekil 2'de verilmiştir.

Beton içinde kullanılmış olan çelik teller numuneler $1 / 3$ ölçekli olduğu için bu ölçeğe uygun seçilmiştir. Telin uzunluğu $30 \mathrm{~mm}$ çapı ise $0.55 \mathrm{~mm}$ olarak seçilmiştir (boy/çap oranı 55). Çelik teller $\mathrm{m}^{3^{\prime}}$ de 30 ve $60 \mathrm{~kg}$ olarak kullanılmıştır (Çizelge 3).

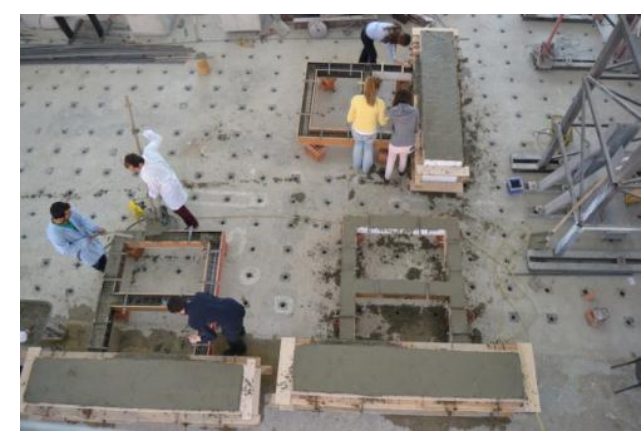

Şekil 2. Numunelerin Üretim Aşaması (Productionphase of thesamples)

Çizelge 3.Numunelerde Kullanılan Olan Çelik Tellerin Özellikleri (Properties of steel wires used in the samples)

\begin{tabular}{cccccc}
\hline Tip & Şekil & Boy & Kesit & Çap & Boy / Çap \\
\hline Kancalı & $30 \mathrm{~mm}$ & Dairesel & 0.55 & 55 \\
& & & & \\
\hline
\end{tabular}

Çizelge 2.Deney Numunelerinin Genel Özellikleri

(The general properties of test sample)

\begin{tabular}{ccc}
\hline $\begin{array}{c}\text { Deney Numunesi } \\
\text { Numaras1 }\end{array}$ & $\begin{array}{c}\text { Deney Numunesinin } \\
\text { Özelliği }\end{array}$ & Deney Numunesinin Şematik Görünüşü \\
\hline & $\begin{array}{c}\text { Normal Betondan Üretilmiş } \\
\text { Referans Numune }\end{array}$ \\
$\mathrm{S}_{1}$ & & \\
& &
\end{tabular}




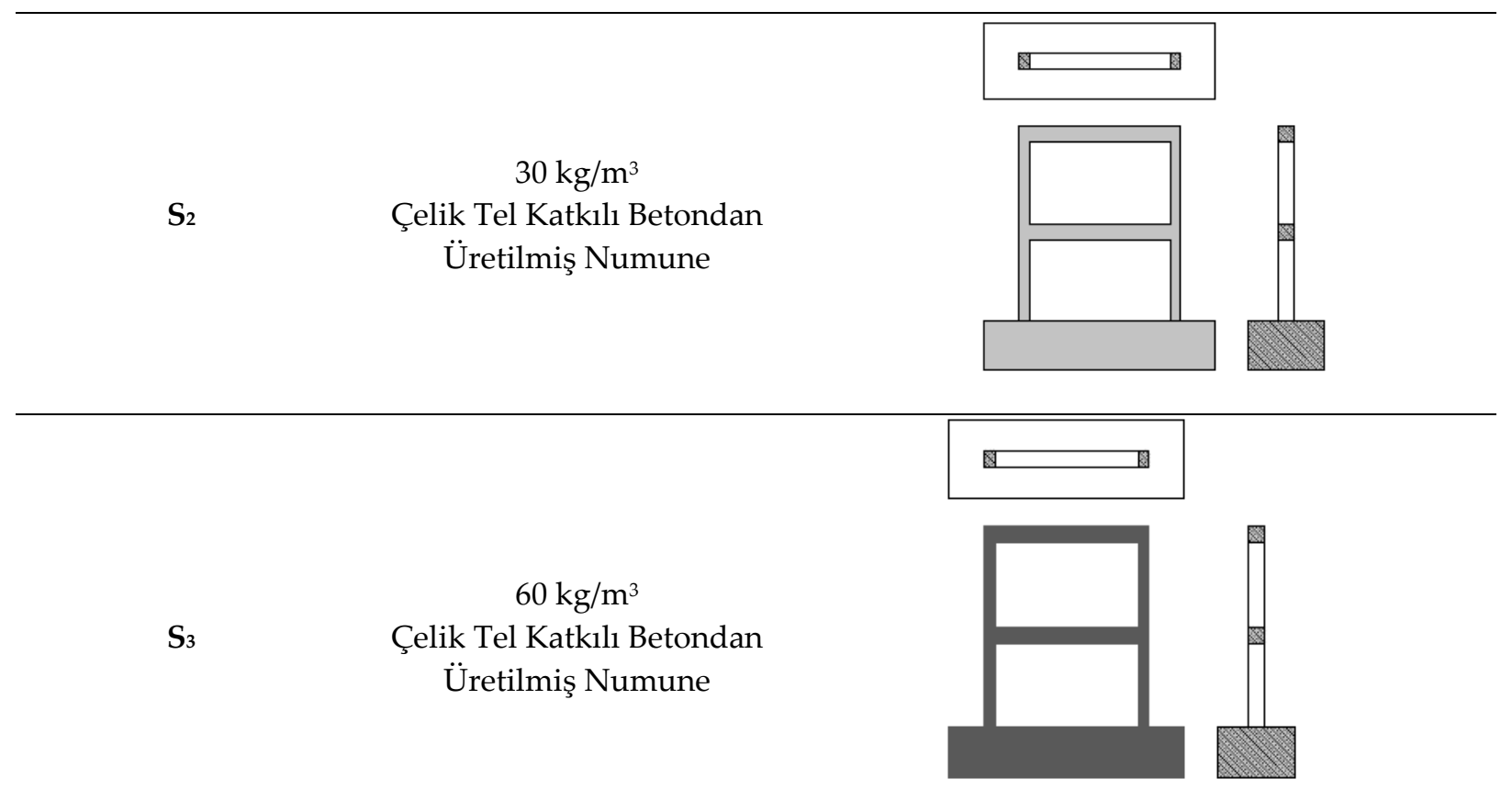

Deneyde kullanılan çelik tel Şekil 3'de çelik telin betonla harmanlanması Şekil 4'de gösterilmiştir. Çelik tellerin beton içinde topaklanmaması için ilk önce suda ıslatılması gerçekleştirilmiş, daha sonra su içinden çıkarılan teller betonunu içinde $30 \mathrm{~kg} / \mathrm{m}^{3}$ ve $60 \mathrm{~kg} / \mathrm{m}^{3}$ olmak üzere iki farklı oranda karıştırılarak üretim gerçekleştirilmiştir. Kullanılan fiberler "Kemeriks" firmasından temin edilmiştir.

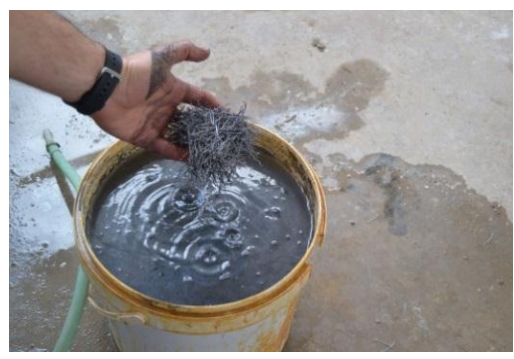

Şekil 3. Deneyde kullanılan çelik tel (The steel wires used in the experiment)

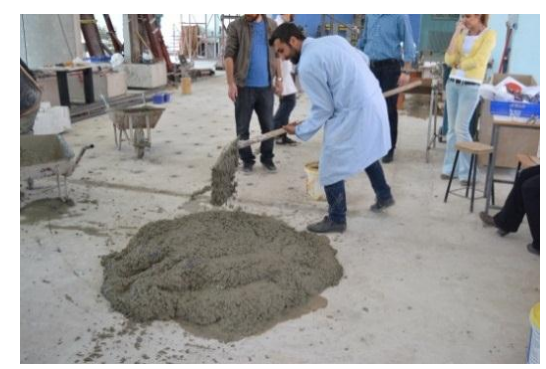

Şekil 4. Deneyde kullanılan çelik telin beton içine karıştırılması (The steel wires mix into the concrete)

Deney numuneleri yatay olarak üretilmiştir ve $18 \mathrm{~mm}$ kalınlığında tek kullanımlık suntalam ile kalıp hazırlanmıştır. Numunelerin üretimi tamamlanıp bakımı yapıldıktan (su kürü uygulaması) 28 gün sonra test işlemlerine başlanmıştır. Üretilen betonarme çerçeveler Selçuk Üniversitesi İnşaat Mühendisliği Bölümü Deprem Laboratuarında depremi temsil eden tersinir tekrarlanır yatay yükler altında test edilmiştir. Şekil 5 ve Şekil 6' da yükleme düzeneği ile ilgili görseller verilmiştir. Deneylerde bilgisayar destekli veri okuma sistemi kullanılarak, gerekli yük ve yer değiştirme okumaları yapılmıştır (Şekil 7-9). 


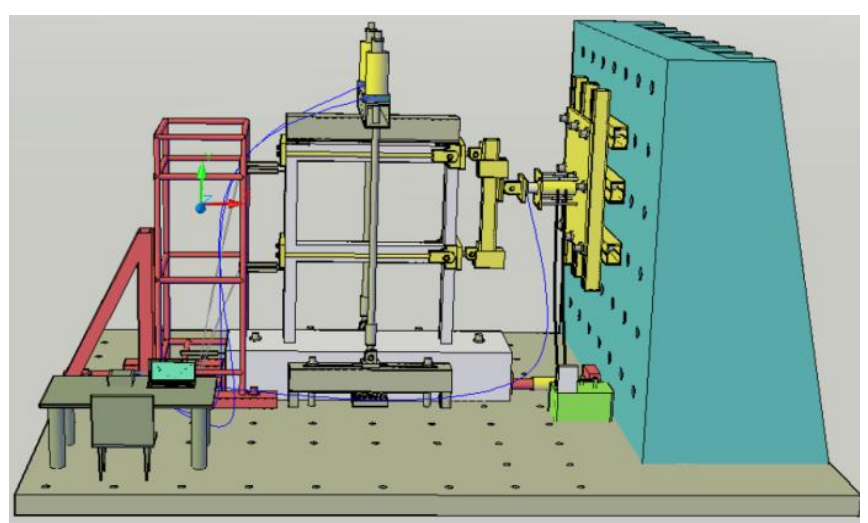

Şekil 5. Yükleme Düzeneği (Experimental setup)

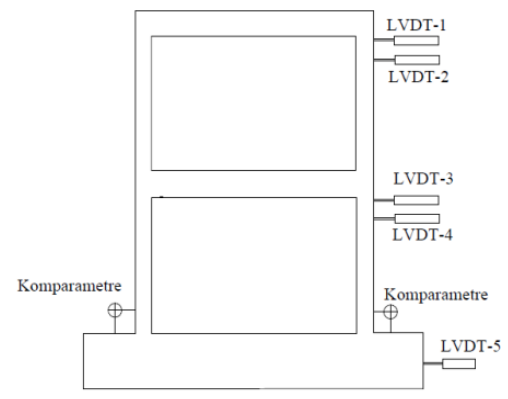
Şekil 7.LVDT ve Dial Gage yerleşimi
(Location of LVDT and DG)

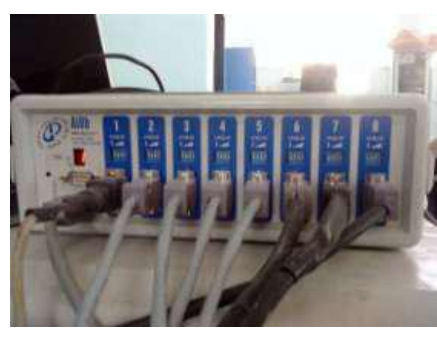

Şekil 8.Veri Toplama Sistemi

(Data acquisition system)

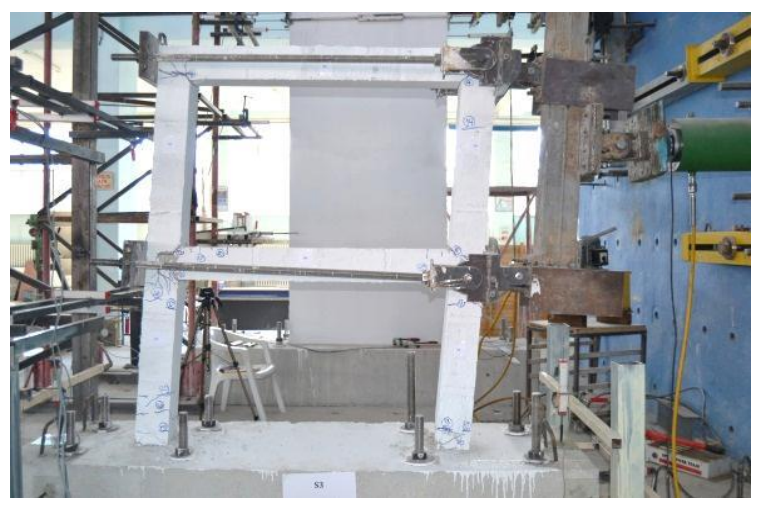

Şekil 6.Üretilen numunelerin test aşaması ( Sample view from testing process )

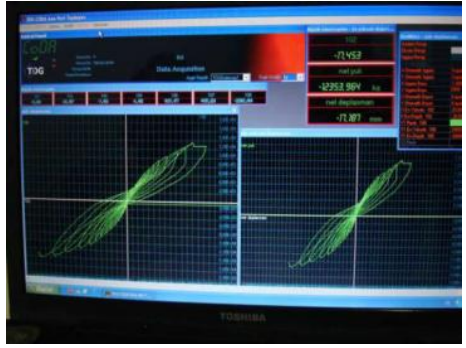

Şekil 9.Bilgisayara Aktarımı (Transfering of data to PC)

Deneylere yük kontrollü olarak başlanıp, betonarme sistemin akma yükünden sonra deplasman kontrollü olarak devam ettirilmiştir. Betonarme elemanların akma yükü, yük-deplasman eğrisinin hatırı sayılır oranda değiştiği an olarak deney sırasında gözlemlenmiştir. Numunelere uygulanacak olan yatay yük düzenek sayesinde üst ve alt katlarda farklı seviyelerdedir. Üçgen yük dağılımını temsil etmesi amaciyla üst kata $2 \mathrm{~F}$ alt kata ise $\mathrm{F}$ kadar bir yatay yük etki ettirilmiştir. Yatay yükün haricinde numunelerde bulunan kolonlara normal kuvvet etki ettirilmemiştir. Dolayısıyla testler eğilme etkisi altında gerçekleştirilmiştir.

Deneylerde deplasman okumalarının yapılabilmesi için beş adet $100 \mathrm{~mm}$ kapasiteli LVDT (Linear Vertical Displacement Transducer) adı verilen deplasman ölçer çerçevelere bağlanmıştır. LVDT'lerden elde edilen deplasman değerleri ile deney düzeneğine bağlı bulunan yük hücrelerinden yapılan yük okumaları neticesinde üç farklı deney numunesinin $\left(S_{1}, S_{2}\right.$ ve $\left.S_{3}\right)$ yük-deplasman grafikleri çizilmiştir.

\section{DENEY SONUÇLARI (CONCLUSIONS OF EXPERIMENT)}

Üretilen betonarme çerçevelerin Selçuk Üniversitesi İnşaat Mühendisliği Bölümü Deprem Laboratuarında depremi temsil eden tersinir tekrarlanır yatay yükler altında test edilmesi sonucunda bilgisayar destekli veri okuma sistemi kullanılarak, gerekli yük ve yer değiştirme okumaları yapılmıştır ve üç farklı deney numunesinin $\left(S_{1}, S_{2}\right.$ ve $\left.S_{3}\right)$ yük-deplasman grafikleri Şekil 10-12'de numunelere ait yük-deplasman grafikleri verilmiştir. Grafiklerde yatay eksen mm cinsinden deplasman düşey eksen ise $\mathrm{kg}$ cinsinden yatay kuvvettir. 


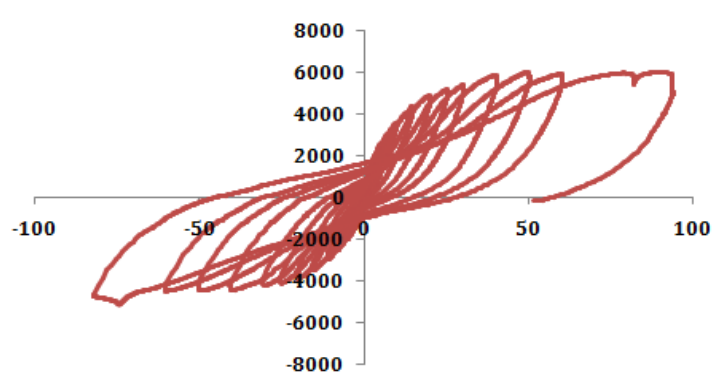

Şekil 10.Sı numunesinin Yük-Deplasman Grafiği (Load-Displacementcurve of $\mathrm{S}_{1}$ )

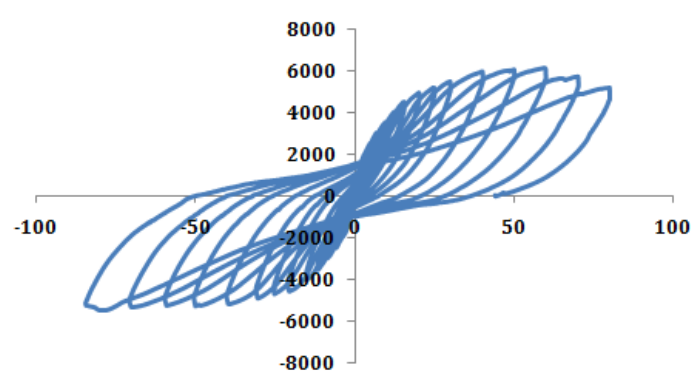

Şekil 11.S2 Numunesinin Yük-Deplasman Grafiği (Load-Displacementcurve of $\mathrm{S}_{2}$ )

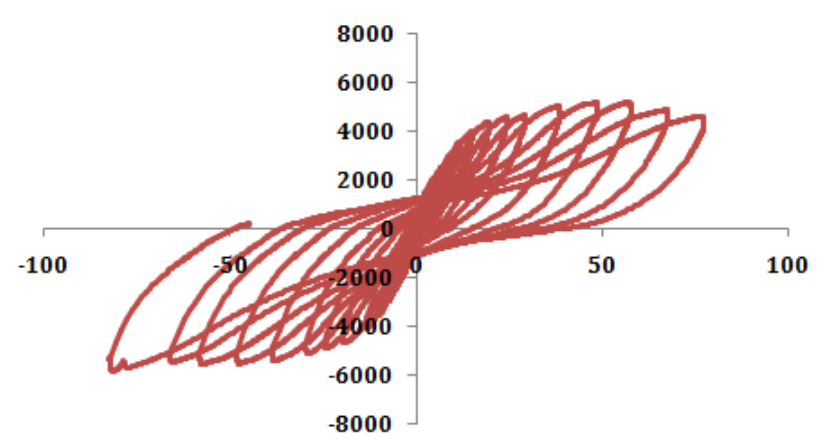

Şekil 12.S3 Numunesinin Yük-Deplasman Grafiği (Load-Displacementcurve of $\mathrm{S}_{3}$ )

Üç farklı deney numunesinin $\left(S_{1}, S_{2}\right.$ ve $\left.S_{3}\right)$ yük-deplasman grafikleri zarf eğrisi şekline dönüştürülmüş ve TDY-2007' de verilen bina hasar sınırları da işaretlenerek Şekil 13-15'de verilmiştir. 


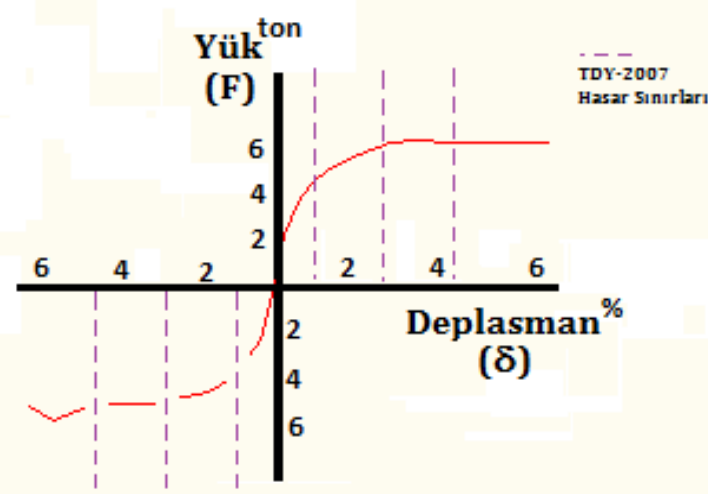

$s_{1}$ Yük-Deplasman Eğrisi

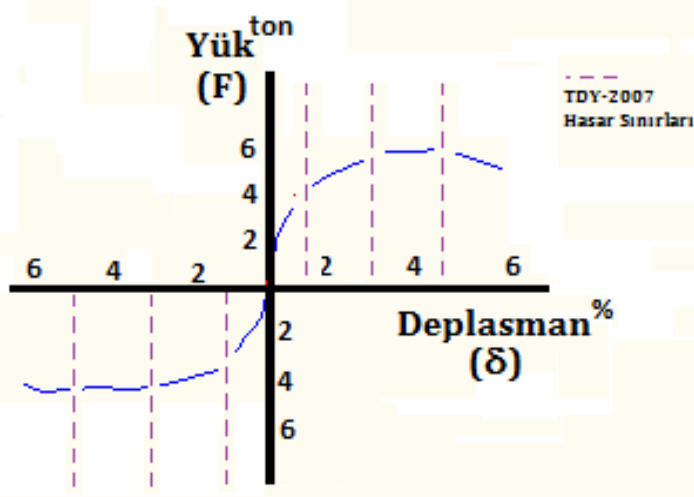

$S_{2}$ Yük-Deplasman Eğrisi

Şekil 14.S2 Zarf Eğrisi

(Capacity curve of $\mathrm{S}_{2}$ )

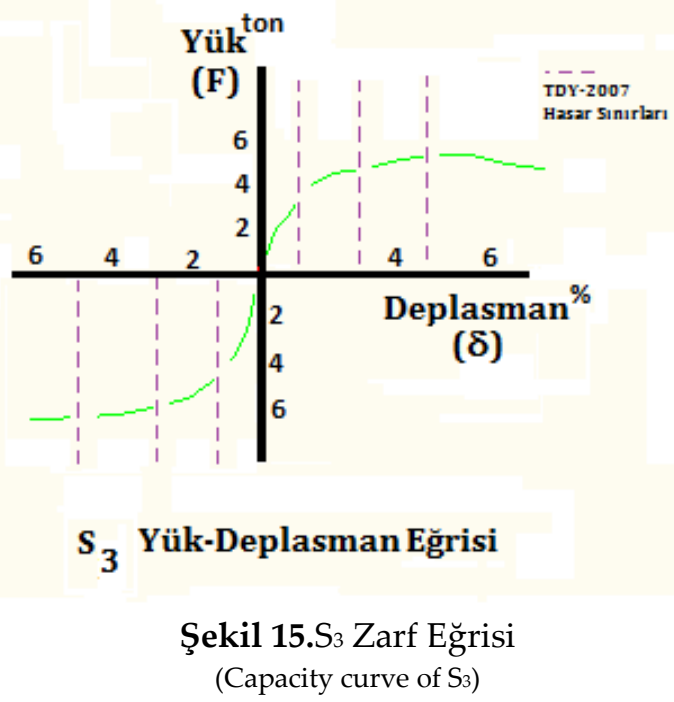

Deneyler sırasında elemanlarda her bir yük kademesinde hasarlar oluşmuş bu hasarlarla beraber rijitlik azalımı meydana gelmiştir. Şekil 16'de ise numunelerin rijitlik azalımlarını karşılaştırmalı olarak verilmiştir. Şekil 17-19' da ise üç farklı deney numunesinin $\left(S_{1}, S_{2}\right.$ ve $\left.S_{3}\right)$ deney öncesi ve sonrası resimleri verilmiştir. 


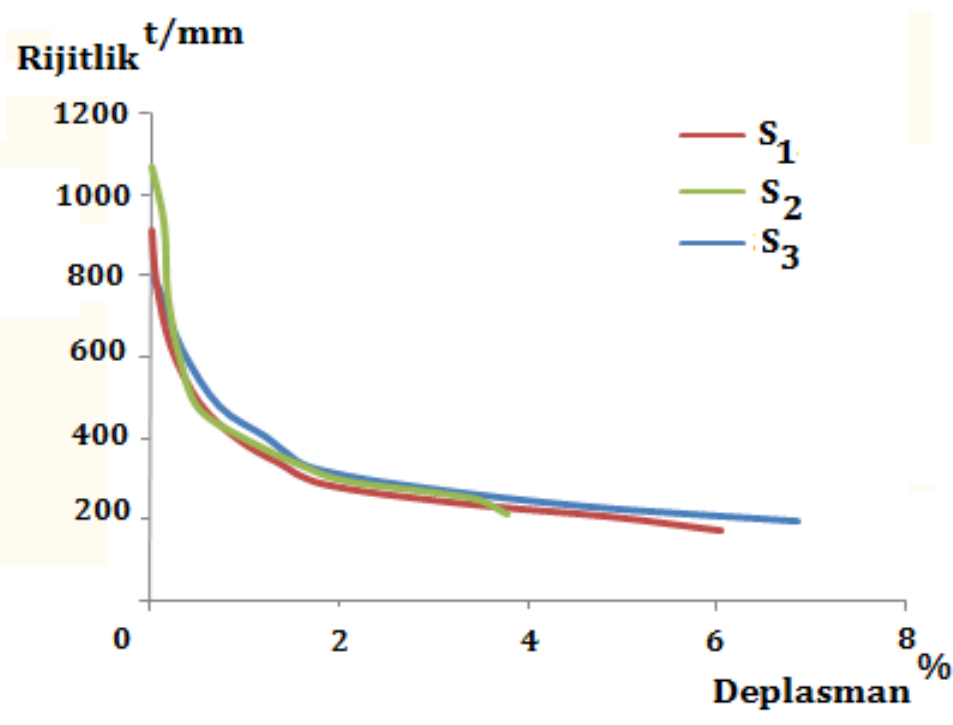

$s_{1} \cdot s_{2} \cdot s_{3}$

Karşılaştırmalı Rijitlik Azalım Eğrileri

Şekil 16.Rijitlik Azalım Grafiği

(Stiffness degradation curves )

Deney Öncesi
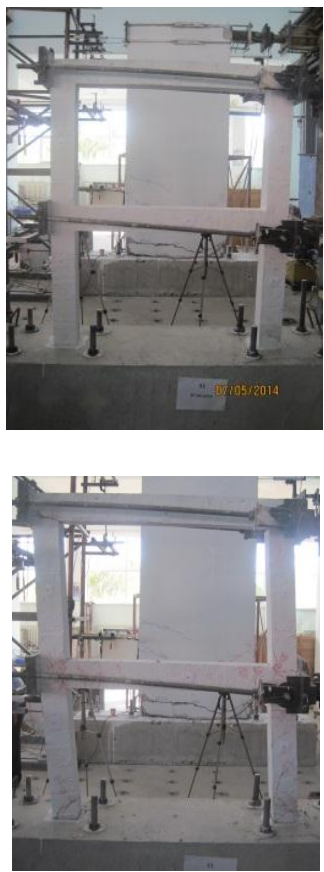

Şekil 17.(S $(F \max =5968$ kg))
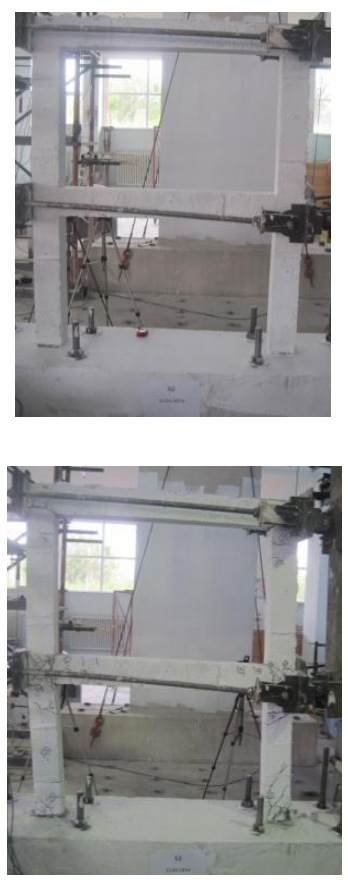

Şekil 18.(S2 (Fmax=6134 kg))
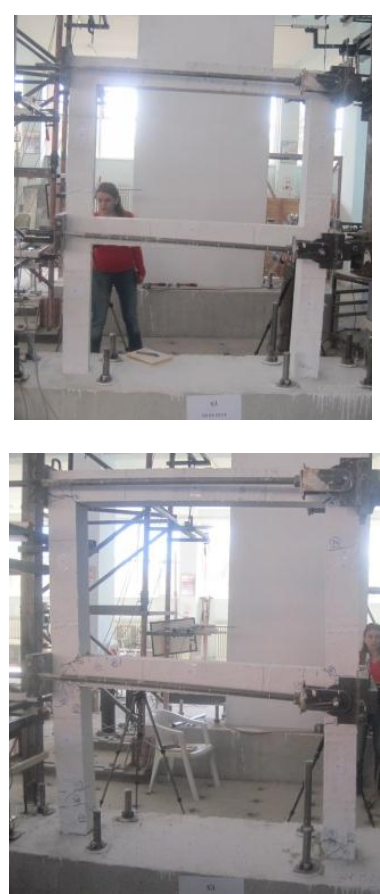

Şekil 19.(S3 $($ Fmax $=5556 \mathrm{~kg}))$ 


\section{SONUÇLAR, TARTIŞMA ve ÖNERİLER (CONCLUSION, DISCUSSION and SUGGESTIONS)}

Çalışma sonunda, beton içinde belirli oranda çelik tel kullanımının betonarme çerçevelerin deprem yükü etkisi altındaki davranışına olan etkisi gözlemlenmiş ve aşağıda özetlenen sonuçlara ulaşılmıştı;;

1. $\quad S_{2}$ numunesinin yatay yük taşıma kapasitesi açısından deprem performansının $S_{1}$ ve $S_{3}{ }^{\prime} \mathbf{e}$ göre bir miktar daha iyi olduğu görülmüştür.

2. $S_{2}$ numunesinin başlangıç rijitlik değerinin $S_{1}$ ve $S_{3}^{\prime} e$ göre daha iyi olduğu görülmektedir. Fakat ilk çatlama ile beraber tüm çerçevelerde rijitlik değerleri birbirlerine çok yaklaşmıştır.

3. S3 numunesinin yatay yük taşıma kapasitesinin $S_{2}{ }^{\prime}$ ye ve $S_{1}{ }^{\prime} e$ göre daha kötü olması, çelik tel miktarının artmasının yapının davranışına her zaman olumlu etki yapmadığı da sonucunda ulaştırmaktadır. Beton elemanlar ve basit kiriş deneyleri üzerinde yapılan literatürdeki diğer çalışmalarda da benzer sonuçlar elde edilmiştir. Fakat literatürde özellikle kirişler üzerinde yapılan deneylerde çelik tellerin kesit sünekliğindeki pozitif etkisi bu çalışmada çerçeve sünekliğinde gözlemlenmemiştir.

4. $\quad \mathrm{S}_{2}$ ve $\mathrm{S}_{3}$ numunelerinde özellikle kirişlerde oluşan hasarlar $\mathrm{S}_{1}{ }^{\prime} \mathrm{e}$ göre oldukça sinırlı miktarlarda kalmıştır. Bu durum çelik telin çatlak oluşumunu geciktirdiği sonucunu ortaya çıkarmaktadır ve beklenen bir sonuçtur.

5. Çelik tel kullanılsın yada kullanılmasın tüm deney numuneleri TDY-2007'nin istemiş olduğu global performans seviyesine ulaşmıştır. Bu durum TDY-2007 ilkelerine göre tasarlanan bir yapının deprem performansının yeterli olacağını da göstermektedir.

6. Çelik tellerin optimum bir değerinin olması gerektiği yapılan bu üç deneyden gözlemlenmektedir. Optimum değer için ise çok sayıda farklı oranlarda deney yapmak gerektiği ise açıkır. Bu araştırmadan yapılacak deneylerde fiber için üst limitin $60 \mathrm{~kg} / \mathrm{m}^{3}$ seçilmesi gerektiği görülmüştür. Literatürdeki diğer çalışmalarda da üst değer olarak bu seviyede fiber önerilmektedir.

7. Deneylerde özellikle kolonlarda plastik mafsal boylarının çelik tel kullanımı ile değiştiği gözlemlenmiştir. Plastik mafsal boyları kolonlarda $0.35 \mathrm{~h}$ ile $0.9 \mathrm{~h}$ arasında değişmektedir. Bu durum TDY-2007' de yer alan 0.5h plastik mafsal boyu kabulünün ortalama değer olarak doğru olduğunu ama yinede özel üretilmiş bu tarz betonlar için değişimin irdelenmesi gerekeceğini de göstermektedir.

8. Beton basınç dayanımını çok fazla etkilememiş olan çelik tellerin çerçeve davranışında pozitif bir etkiye sahip olması, çelik tel kullanımı ile çatlamış kesit eğilme rijitliklerindeki azalmanın klasik betonarmeden farklı olduğunu, elemanlarda çatlama ile beraber $0.4 \sim 0.6$ oranında olması beklenen eğilme rijitliği kaybının daha az gerçekleştiğini göstermektedir.

Çelik tel kullanılarak üretilen betonların davranışına yönelik literatürde çok sayıda çalışma olmakla beraber, bu çalışmada test edilen çerçeve deneyleri ile deprem performansının değişiminin irdelenmesi gibi bir çalışmanın henüz gerçekleştirilmemiş olması ve elde edilen sonuçlar, çalışmanın devamı açısından da son derece önemlidir. Ayrıca çalışmada beton içine belirli oranlarda karıştııılan çelik tellerin metal geri dönüşümü yöntemi ile üretilebilecek olması betonarme yapılarda alternatif atık malzeme kullanımı açısından da son derece önemlidir.

Rekabetin her geçen gün arttığı piyasa koşullarında, firmalar yetenek ve kapasitelerini yeni ürünlerle desteklemektedirler. Özellikle geleneksel ve prefabrike betonarme inşaat sektöründe firmalar depreme göre yapı davranışını iyileştirecek yeni malzemeler ve yaklaşımları aramaktadırlar. Bu çalışma akabinde yapılacak çeşitli oranlarda çelik tel ihtiva eden çerçeve deneyleri ile konvansiyonel ya da prefabrike olarak üretilmiş olan betonarme yapılarda beton içine uygun oranda çelik tel katılması suretiyle yapının deprem davranışının değişimi irdelenebilecektir.

\section{BİLGÍLENDİRME (ACKNOWLEDGEMENT)}

Bu çalışma 2014 yılında Selçuk Üniversitesi İnşaat Mühendisliği Bölümünde bir bitirme tezi olarak lisans öğrencileri ile beraber gerçekleştirilmiştir. Çalışma Selçuk Üniversitesi Mühendislik Fakültesi tarafından organize edilen SUMOPP (1. Öğrenci Bitirme Projesi Pazarı)'nda Çevre tematik alanında 3. Olmuştur. 
Yazarlar deneylerin yapılması sırasında yardımlarından dolayı S.Ü. İnşaat Müh. Öğr. Üyesi Doç. Dr. Hasan Hüsnü KORKMAZ ve Teknisyen Yüksel ÇİFTÇİ'ye teşekkür ederler.

\section{KAYNAKLAR (REFERENCES)}

Aktaş, B., 2007; “Çelik Lifli Hafif Beton İle İmal Edilmiş Betonarme Kirişlerin Mekanik Özelliklerinin İncelenmesi", Yüksek Lisans Tezi, Erciyes Üniversitesi Fen Bilimleri Enstitüsü, Kayseri

Craig, R. J.,Patel, C., 1982; "Behavior of joints using reinforced fibrous concrete In": Fiber Reinforced Concrete International Symposium, AmericanConcreteInstitute, Detroit

Ramesh, K.,Seshu, D.R., Prabhakar, M., 2003; "Constitutive behavior of Confined fibre reinforced concrete under axial compression", CementEConcreteComposites 25, 343-350.

Shah, S.,P, Rangan, B., V., 1970;" Effects of reinforcements on ductility of concrete" Proc ASCE ;96(576):1167-84

Sheikh, A.,S., 1982; " A comparative study of confinement models" ACI J Mater , 79 (04): 296-306.

Taşdemir, M. A., 1999; " Çelik Tel Takviyeli Yüksek Dayanımlı Betonların Mekanik Davranışı", Çelik Tel Donatılı Betonlar Sempozyumu, İstanbul.

TS-500-2000, 2000; Betonarme Binaların Yapım yönetmeliği (Betonarme Yapıların Hesap ve Yapım Kuralları), Ankara.

Türk Deprem Yönetmeliği, 2007; Deprem Bölgelerinde Yapılacak Binalar Hakkında Yönetmelik, Ankara.

Ünal, O.,Uygunoğlu, T., Gençel, O., 2007; “Çelik Liflerin Beton Basınç ve Eğilme Özeliklerine Etkisi”, Pamukkale Üniversitesi Mühendislik Fakültesi, Mühendislik Bilimleri Dergisi, Cilt 13, Sayı 1, Sayfa 23-30 